\title{
TRATAMENTO MINIMAMENTE INVASIVO DE LESÕES CARIOSAS EM ODONTOPEDIATRIA
}

\section{MINIMALLY INVASIVE TREATMENT OF CARIOUS LESIONS IN PEDIATRIC DENTISTRY}

Isabelly Da Costa Reis ${ }^{1}$, Adílis Alexandria ${ }^{2}$, Maysa Lannes Duarte ${ }^{3}$, Aline Dos Santos Letieri ${ }^{3}$, Thais Rodrigues Campos Soares ${ }^{1^{*}}$.

\author{
${ }^{1}$ Universidade Salgado de Oliveira, Niterói, RJ, Brasil. \\ 'Universidade do Estado do Rio de Janeiro, Rio de Janeiro, RJ, Brasil. \\ ${ }^{3}$ Universidade Federal do Rio de Janeiro, Rio de Janeiro, RJ, Brasil. \\ *dra.thaissoares@yahoo.com.br
}

Recebido em: 08/05/2020; Aceito em: 27/10/2020.

\section{RESUMO}

Dificuldades no atendimento odontológico das crianças, devido à necessidade de controle do comportamento e de suporte familiar adequado, além de peculiaridades relativas à anatomia dos dentes decíduos, suscitam o uso de técnicas de mínima intervenção para o controle da cárie dentária. Logo, o objetivo do presente trabalho foi realizar uma revisão bibliográfica sobre 0 tratamento minimamente invasivo de lesões de cárie em dentes decíduos, abordando as características, indicações e limitações de diferentes técnicas dentro desse conceito. O controle de biofilme sem selamento dentário é uma abordagem na qual nenhum tipo de material restaurador é colocado para selar as cavidades, sendo instituída a higiene bucal de modo eficiente como estratégia para paralisar as lesões de cárie. O selamento da lesão sem remoção de tecido cariado prevê a utilização de selantes resinosos ou coroas metálicas diretamente sobre as cavidades, sem remoção prévia de tecido cariado. Já a remoção seletiva de cárie seguida de restauração é a técnica mais aceita e utilizada em odontopediatria, sendo atualmente considerado o padrão ouro, em detrimento da remoção total de tecido cariado. Apesar de a mínima intervenção ser bem aceita pelas crianças, sua aceitabilidade pelos responsáveis e odontopediatras ainda é questionável. Verificou-se que todas essas técnicas se apresentam como alternativas eficazes para o tratamento minimamente invasivo em odontopediatria. Entretanto, é fundamental o entendimento, participação e comprometimento dos familiares, tendo em vista que o controle do biofilme e da dieta possuem papel fundamental para garantir o sucesso desses tratamentos.

Palavras-chave: Cárie Dentária. Criança. Dente Decíduo. Odontopediatria. Tratamento Conservador.

\section{ABSTRACT}

Difficulties in dental care for children, due to the need to behavior control and adequate family support, in addition to peculiarities regarding the anatomy of primary teeth, call for the use of minimal intervention techniques for the control of 
dental caries. Therefore, the objective of the present study was to carry out a bibliographic review on the minimally invasive treatment of caries lesions in primary teeth, addressing the characteristics, indications, and limitations of different techniques within this concept. The control of biofilm without dental seal is an approach in which no type of restorative material is placed to seal the cavities, with oral hygiene being efficiently instituted as a strategy to paralyze caries lesions. Sealing the lesion without removing carious tissue requires the use of resinous sealants or metallic crowns directly over the cavities, without prior removal of carious tissue. In turn, selective caries removal followed by restoration is the most accepted and used technique in pediatric dentistry, and is currently considered the gold standard, to the detriment of total removal of carious tissue. Although the minimum intervention is well accepted by children, its acceptability by guardians and pediatric dentists is still questionable. It was observed that all these techniques are effective alternatives for minimally invasive treatment in pediatric dentistry. However, the understanding, participation, and commitment of the family members is essential, considering that the control of biofilm and diet have a fundamental role to guarantee the success of these treatments.

Keywords: Child. Conservative Treatment. Dental Caries. Pediatric Dentistry. Deciduous Tooth.

\section{INTRODUÇÃO}

A cárie dentária é uma doença crônica que apresenta elevada prevalência em todo o mundo, sendo considerada um problema de saúde pública. As lesões de cárie não tratadas afetam 621 milhões de crianças, sendo a 10ª condição mais prevalente no planeta (KASSEBAUM et al., 2015). No Brasil, em 2010, as crianças aos 5 anos de idade possuíam uma média de 2,43 dentes com experiência de cárie, sendo que mais de $80 \%$ desse índice era composto por dentes cariados (BRASIL, 2012). Em países subdesenvolvidos, a incidência da doença não diminuiu significativamente e o seu tratamento, na maioria das vezes, não é realizado, ou a extração dentária acaba sendo o procedimento mais comumente empregado, uma vez que os custos dos tratamentos restauradores são altos, tornando-os alternativas inviáveis para grande parte da população (KASSEBAUM et al., 2015).

Com o avanço das pesquisas em cariologia e o surgimento das restaurações adesivas, possibilitou-se o emprego de terapêuticas ainda mais conservadoras. Logo, surgiu o conceito de odontologia minimamente invasiva, que preocupa-se em diagnosticar a cárie precocemente e oferecer a melhor estratégia de tratamento, sempre com a mínima intervenção operatória possível, para prevenção e controle da doença (TUMENAS et al., 2014).

A abordagem de mínima intervenção pode ser extremamente útil para a odontopediatria, uma vez que técnicas que evitam o uso anestesia local são extremamente benéficas para evitar ou minimizar a ansiedade gerada pelo tratamento (KIDD, 2012; SCHWENDICKE; FRENCKEN; INNES, 2018). Além disso, técnicas minimamente invasivas promovem menor geração de aerossóis, o que faz com que a abordagem receba destaque também no contexto da pandemia COVID-19. Dentre os profissionais de saúde, os cirurgiões dentistas 
encontram-se em risco elevado de contaminação pelo coronavírus Sars-Cov-2, ressaltando-se os odontopediatras ou aqueles que cuidam de pacientes infantis, uma vez que as crianças afetadas frequentemente apresentam quadros clínicos assintomáticos podendo, portanto, desempenhar um papel importante na transmissão comunitária da doença (FERRAZZANO; INGENITO; CANTILE, 2020). Por isso, os profissionais devem minimizar o uso de instrumentos rotatórios, optando por procedimentos como restaurações atraumáticas e remoção química de cárie (FINI, 2020).

Em razão da importância da abordagem de mínima intervenção em odontopediatria, este trabalho tem por finalidade realizar uma revisão bibliográfica, do tipo narrativa, sobre o tratamento minimamente invasivo de lesões de cárie em odontopediatria, apresentando suas principais características, indicações e limitações.

\section{METODOLOGIA}

A presente revisão narrativa da literatura foi realizada através de uma busca bibliográfica nas bases de dados Google Acadêmico e PubMed. As chaves de buscas foram formuladas a partir de Mesh terms e sinônimos definidos pelos Descritores em Ciências da Saúde (DeCS). As buscas foram realizadas utilizando descritores nas línguas portuguesa e inglesa na base Google Acadêmico e apenas na língua inglesa no PubMed. Foram empregados descritores como: "odontologia minimamente invasiva"; "minimally invasive dentistry"; "odontopediatria"; "pediatric dentistry"; "dente decíduo"; "tooth deciduous". A busca foi atualizada até outubro de 2020 e não foi empregada nenhuma restrição quanto ao idioma nem ao ano de publicação.

Foram incluídos apenas os artigos que as autoras consideraram mais relevantes sobre o tema, dentre aqueles que abordassem pelo menos uma técnica de tratamento minimamente invasivo de lesões de cárie em dentes decíduos, tratando das suas indicações e/ou principais limitações.

\section{DESENVOLVIMENTO}

A cárie dentária e suas sequelas causam impacto negativo na qualidade de vida das crianças, influenciando na sua alimentação, fala, autoestima e socialização, podendo afetar até mesmo o seu rendimento escolar (REBELO et al., 2019). A manutenção dos dentes decíduos até o período de esfoliação fisiológica é imprescindível para garantir que suas funções, como mastigação, fonação e deglutição, e a estética sejam preservadas na criança, além de facilitar o estabelecimento correto da posição dos sucessores permanentes. A perda prematura desses dentes é um dos fatores que favorece o estabelecimento de maloclusões na dentição permanente (PAULSSON; SÖDERFELDT; BONDEMARK, 2008).

Para que a criança possa ter uma saúde bucal adequada e uma maior longevidade dos dentes decíduos, necessita-se o esforço dos profissionais de saúde e dos familiares, além da colaboração e aceitação da criança. Uma vez que existem várias dificuldades relativas ao controle do comportamento infantil durante o tratamento restaurador convencional, opções menos invasivas para o 
tratamento de lesões cariosas em dentes decíduos são uma alternativa interessante. Nesse contexto, o tratamento da cárie deve contemplar, sempre que possível, uma abordagem de mínima intervenção, sendo realizado de forma abrangente, com métodos de prevenção e participação do paciente e responsáveis. Essas técnicas possuem um amplo alcance social, podendo até mesmo diminuir o tempo de cadeira no dentista, se forem executadas de forma eficiente (KIDD, 2012; TUMENAS et al., 2014).

Apesar disso, o tratamento da cárie dentária em dentes decíduos é, ainda hoje, um assunto controverso na literatura. Questões como o tempo de permanência do dente na cavidade bucal levam a questionamentos sobre o emprego de algumas das técnicas restauradoras tradicionais. Nesse contexto, o uso tópico de flúor, controle de biofilme e de dieta são fatores importantes que devem ser levados em consideração no momento do planejamento do tratamento em odontopediatria (ANTUNES; NARVAI; NUGENT, 2004).

Existem diferentes técnicas que podem ser empregadas para 0 tratamento das lesões de cárie em dentes decíduos. No presente artigo, serão abordadas as técnicas minimamente invasivas, como o controle de biofilme sem selamento da lesão, selamento de cavidades sem remoção de tecido cariado e remoção seletiva de cárie seguida de restauração.

\section{Controle de biofilme sem selamento cavitário}

Para que a cárie dentária possa ser controlada, o paciente deve ser analisado do ponto de vista biológico, psicológico e social (ANTUNES; NARVAI; NUGENT, 2004). O tratamento de controle de biofilme sem selamento cavitário consiste em uma abordagem na qual nenhum tipo de material é colocado para selar as lesões de cárie. Para o sucesso dessa técnica, as cavidades presentes devem apresentar uma abertura que permita um efetivo controle de biofilme local. Caso isso não seja possível, deve-se tornar as cavidades amplas e expulsivas o suficiente, a fim de que a higienização local possa ser realizada de maneira eficiente. $O$ controle da placa bacteriana é realizado com a escovação dentária regular caseira, uso do fio dental e uso de enxaguatórios bucais, quando necessário. Logo, as técnicas de higiene bucal devem ser passadas aos pacientes e aos seus responsáveis de maneira cuidadosa e reforçada, a fim de que eles possam realizá-las eficientemente em casa e, com isso, garantir maiores taxas de sucesso do tratamento. Além disso, é fundamental que sejam dadas orientações sobre controle da dieta, enfatizando a redução do consumo de açúcares fermentáveis (KIDD, 2012; KIDD; FEJERSKOV; NYVAD, 2015).

Além disso, é realizada a aplicação tópica de flúor na dentina cariada e, nos casos de lesões muito profundas e/ou com sensibilidade associada, é feita a colocação de uma camada de cimento de ionômero de vidro (CIV) como forro no fundo da cavidade. Com o tempo haverá a estabilização da lesão através de deposição de dentina esclerosada e terciária (KIDD, 2012).

Essa abordagem é considerada rápida e de fácil execução, sendo bem tolerada até mesmo por pacientes nervosos, ansiosos ou fóbicos, além de não haver necessidade de uso de anestesia local. Por outro lado, é primordial ter uma boa higiene bucal e exige um grande comprometimento e colaboração dos pacientes e cuidadores para que a técnica possa ser bem-sucedida, (KIDD, 
2012; KIDD; FEJERSKOV; NYVAD, 2015), sendo essa uma das suas maiores limitações.

Como nessa abordagem não se utiliza nenhum tipo de material restaurador, ela é considerada uma técnica de baixo custo e de fácil execução. Por ser uma técnica que não utiliza anestesia local, é bem aceita pelas crianças, principalmente por aquelas portadoras de necessidades especiais (KIDD, 2012). Devido às suas características operatórias, ela poderia ser amplamente utilizada em serviço público, porém a grande dificuldade para realização do seu controle e proservação dificultam sua utilização em larga escala.

Sua principal desvantagem é que essa técnica coloca a responsabilidade do controle do biofilme, através da higiene oral diária e controle da dieta, aos pais e responsáveis (KIDD, 2012). Nesse ponto de vista, ela torna-se bastante controversa, uma vez que existe uma grande dificuldade de escovação e controle do consumo de açúcares, principalmente em crianças de pouca idade (UNKEL et al., 1995) e de baixa renda (RODE et al., 2012), o que pode influenciar diretamente no sucesso da técnica. Além disso, pouco se sabe sobre a aceitabilidade desta técnica pelos responsáveis e até mesmo pelos profissionais, uma vez que a odontologia convencional, com a qual as pessoas estão mais familiarizadas, envolve o uso de materiais restauradores. Além disso, ela não contempla uma melhora na estética, que é uma queixa cada vez mais frequente entre pais e pacientes que buscam por tratamento odontológico. Em contrapartida, os tratamentos convencionais em dentes decíduos usam materiais odontológicos restauradores estéticos (DONMEZ et al., 2016).

Apesar dessas questões, seu uso deve ser considerado, uma vez que essa técnica mostrou apresentar boa taxa de sucesso clínico, apresentando até mesmo menor porcentagem de progressão das lesões do que a taxa de recorrência (presença de cáries secundárias) quando realizadas restaurações convencionais (SANTAMARÍA et al., 2018), comprovando que mesmo a técnica de não remoção mecânica de tecido cariado favorece a paralisação de lesões de cárie em dentina (FERREIRA et al., 2012; BANERJEE et al., 2017).

Além disso, há evidência científica de que a associação entre o controle dos fatores etiológicos da cárie, o uso de produtos fluoretados e selantes são de fato alternativas eficazes para a paralisação ou diminuição da progressão de lesões iniciais em Odontopediatria. A opção por esse tipo de manejo clínico não operatório deve ser realizada levando em consideração o correto diagnóstico das lesões, custo e disponibilidade dos tratamentos, características individuais dos pacientes, além das preferências do profissional e dos pacientes e suas famílias. Logo, a técnica não restauradora de controle de biofilme sem selamento cavitário é uma boa opção diante de casos como: paciente que tenha dificuldade de cooperar com o tratamento; presença de cavidades amplas e expulsivas, nas quais a realização de restaurações diretas convencionais apresentem prognóstico duvidoso ou tempo limitado de vida útil do dente na cavidade bucal (ABOPED, 2020).

\section{Selamento sem remoção de tecido cariado}

A técnica de selamento cavitário sem remoção de tecido cariado consiste na utilização de um selante resinoso ou uma resina de baixa viscosidade para 
vedar lesões não cavitadas (HOLMGREN et al., 2014) ou até mesmo cavidades oclusais pouco extensas. Ela é indicada apenas para lesões que atinjam até a metade externa da dentina. No caso de lesões oclusais, estas devem possuir uma abertura de até $3 \mathrm{~mm}$ (ABOPED, 2020). Sua realização consiste apenas na limpeza da superfície, através de profilaxia, e posterior realização do procedimento restaurador, sem realizar remoção de tecido cariado nem qualquer tipo de instrumentação da cavidade (BAKHSHANDEH; QVIST; EKSTRAND, 2012; ALVES et al., 2017; DIAS et al., 2018).

O selamento da dentina cariada de lesões oclusais cavitadas em dentes decíduos apresentou altas taxas de sucesso clínico e radiográfico em dois ensaios clínicos controlados e randomizados, assemelhando-se à realização da remoção seletiva seguida de restauração resinosa, considerada padrão-ouro na literatura (HESSE et al., 2014; DIAS et al., 2018). Essa técnica mostrou-se eficiente até mesmo na dentição permanente (BAKHSHANDEH; QVIST; EKSTRAND, 2012; ALVES et al., 2017). Apesar de ainda pouco estudada em odontopediatria, verificou-se que ela reduz o tempo de cadeira e não eleva a ansiedade das crianças, sendo uma boa alternativa para esses pacientes (DIAS et al., 2018). Sua atuação promove o controle da doença através do restabelecimento do equilíbrio bucal, sendo uma técnica operatória simples e menos invasiva, representando uma opção viável para o tratamento de lesões pequenas ou não cavitadas (ALVES et al., 2017; ABOPED, 2020). Recomendase que, diante de situações de dúvida sobre restaurar ou não um elemento dentário, deve-se optar pela reavaliação (ABOPED, 2020).

No entanto, uma de suas limitações é a necessidade de adesão do paciente ao acompanhamento regular a fim de controlar a ocorrência de falhas clínicas desses selantes ou restaurações (ALVES et al., 2017). O uso de selantes resinosos possui eficácia clínica duvidosa, uma vez que seu sucesso depende da sua permanência fisicamente aderido à superfície dentária. Logo, o acompanhamento clínico e radiográfico dos dentes selados é fundamental para avaliação do sucesso dessa técnica. As falhas mais comuns estão relacionadas a desadaptação do material restaurador e a baixa resistência à mastigação, quando comparada aos tratamentos restauradores convencionais (HESSE et al., 2014).

Ainda dentro dessa abordagem, foi desenvolvido um novo método de tratamento, denominado Técnica de Hall, que consiste na cimentação de coroas de aço pré-fabricadas, usando cimento de ionômero de vidro, sobre molares decíduos com lesões cavitadas. Nessa técnica, não há uso de anestesia local, remoção de cárie ou preparação dentária de qualquer tipo. Sua principal indicação são dentes decíduos com grande perda de estrutura devido à cárie (INNES et al., 2006). Como vantagem, as coroas de aço inoxidável são de baixo custo e podem proporcionar ao dente muitos anos em função, mantendo o perímetro do arco dentário, preservando a saúde gengival e a função. Além disso, a cimentação dessa coroa irá auxiliar na remineralização e no controle da progressão de cárie sem uma etapa laboratorial para sua confecção e requer pouco tempo de trabalho (INNES et al., 2006; INNES; EVANS; HALL, 2009).

Nessa técnica, as coroas formam uma barreira física que auxilia a remineralização do dente, sendo considerado um método menos invasivo, uma vez que não requer nenhum preparo do elemento ou remoção de tecido cariado 
(INNES; EVANS; HALL, 2009). A taxa de sucesso para essa técnica foi de $98 \%$ após 1 ano e mostrou eficácia superior em relação à restauração convencional. Além disso, a técnica de Hall tem mostrado resultados mais favoráveis para a saúde pulpar e maior longevidade do dente em estudos retrospectivos e relatos de casos (INNES; EVANS; STIRRUPS, 2011; INNES et al., 2017).

No entanto, sua principal desvantagem é a ocorrência de contatos oclusais prematuros em quase todos os casos, devido às diferenças na anatomia oclusal e a ausência de desgastes ou preparos dentários prévios à cimentação (VAN DER ZEE; VAN AMERONGEN, 2010; KIDD, 2012). Porém, já foi demonstrado que o restabelecimento da oclusão ocorre dentro de um período entre 15 e 30 dias (VAN DER ZEE; VAN AMERONGEN, 2010). No entanto, ainda existem dúvidas sobre os possíveis danos ao sistema estomatognático a longo prazo. E, embora exista uma queixa estética em relação ao uso das coroas metálicas, uma vez que o profissional demonstre as vantagens da técnica, entre elas ser menos doloroso e não necessitar de anestesia local, além do fato de os dentes decíduos serem temporários, os responsáveis tendem a concordar com a sua realização e a aceitar melhor o tratamento (VAN DER ZEE; VAN AMERONGEN, 2010; INNES et al., 2017). Outra limitação é a possibilidade de infiltração secundária de cárie, se não houver uma higienização adequada pelo paciente e/ou seus responsáveis (INNES; EVANS; STIRRUPS, 2007), dependendo assim da cooperação e comprometimento deles com o tratamento. No geral, acredita-se que a Técnica Hall consiste em uma opção de tratamento eficaz para dentes molares decíduos cariados, devido a suas elevadas taxas de sucesso clínico (INNES; EVANS; STIRRUPS, 2007; INNES; EVANS; HALL, 2009; INNES; EVANS; STIRRUPS, 2011).

A Academia Americana de Odontopediatria (AAPD) e a Associação Brasileira de Odontopediatria (ABOPED) chamam atenção para a escassez de estudos clínicos controlados randomizados que comparem o uso de coroas de aço pré-fabricadas para a técnica de Hall com outras restaurações, descrevendo haver evidências de estudos retrospectivos que demonstram maior longevidade de restaurações de coroas de aço pré-formadas em comparação com restaurações de amálgama (AAPD, 2019; ABOPED, 2020). Portanto, recomenda sua realização apenas em crianças de alto risco de cárie, com múltiplas superfícies cavitadas ou lesões grandes, especialmente quando o tratamento requer técnicas avançadas de controle do comportamento, como anestesia geral para execução de procedimentos restauradores (AAPD, 2019).

\section{Remoção seletiva de cárie seguida de restauração}

Existem diferentes nomenclaturas para essa técnica entre os estudos. A fim de padronizar e melhorar o entendimento e a comunicação sobre ela dentre os pesquisadores, profissionais e até mesmo os pacientes, recomenda-se que ela seja chamada de remoção seletiva de tecido cariado (INNES; SCHWENDICKE; FRENCKEN, 2018). O termo remoção parcial de cárie é bastante usado, porém pode transmitir a imagem de que tecido cariado foi deixado acidentalmente no interior da cavidade, denotando negligência por parte do profissional. 
A remoção seletiva de cárie consiste na remoção de tecido cariado de acordo com as características da cavidade a ser tratada. Em lesões superficiais ou moderadas recomenda-se que seja feita a remoção de tecido cariado das paredes pulpares até dentina firme, enquanto em lesões mais profundas, que se estendam até perto da polpa, deve ser realizada a remoção seletiva até dentina mole ou amolecida, a fim de evitar que haja exposição pulpar e aumentando as chances de preservar a saúde e vitalidade da polpa (RICKETTS; INNES; SCHWENDICKE, 2018; SCHWENDICKE; FRENCKEN; INNES, 2018).

É importante observar que essa técnica, assim como todas as demais abordagens minimamente invasivas descritas anteriormente, só é indicada para dentes que tenham vitalidade pulpar e que não apresentem nenhum sinal ou sintoma de acometimento da polpa, como a presença de dor. Outro ponto fundamental é que nessa técnica recomenda-se que a remoção de tecido cariado nas paredes circundantes seja total, isto é, que haja remoção até dentina firme, na qual não haja descoloração e que tenha consistência endurecida, apresentando certa resistência à passagem do escavador manual. Isso irá possibilitar um vedamento marginal satisfatório da restauração, o que irá garantir o sucesso do tratamento. Em geral, o selamento da cavidade é feito através de restauração adesiva, que impossibilite que os microrganismos remanescentes continuem viáveis, impedindo que ocorra progressão da cárie residual (INNES et al., 2016; RICKETTS; INNES; SCHWENDICKE, 2018; SCHWENDICKE; FRENCKEN; INNES, 2018).

O processo patológico no tecido remanescente sofre alterações, uma vez que é submetido a um novo microambiente, havendo diminuição dos microrganismos presentes, maior deposição de dentina secundária e remineralização da lesão, que pode ser constatada através do aumento da quantidade de fósforo e a modificação da coloração e consistência da dentina remanescente, que se torna similar à de lesões inativas (LULA et al., 2009). Antes da realização da restauração, sabe-se que há presença de maior número de microrganismos nos dentes submetidos à remoção seletiva da cárie do que naqueles em que é realizada a remoção completa. No entanto, após a realização do selamento marginal adequado, o nível de colonização torna-se semelhante entre eles. Desse modo, a persistência inicial de bactérias após a remoção seletiva de cárie parece não ser um problema, desde que a restauração seja capaz de promover um vedamento satisfatório (LULA et al., 2009; SINGHAL; ACHARYA; THAKUR, 2016).

Desse modo, atualmente a remoção total de tecido cariado, ou remoção até dentina dura em todas as paredes cavitárias, não é mais indicada. A técnica considerada padrão ouro é a remoção seletiva de tecido cariado, tanto para dentes decíduos quanto para permanentes. Ela preserva os tecidos não desmineralizados e os remineralizáveis, evitando o desconforto e/ou dor durante o procedimento e, com isso, reduzindo a ansiedade frente ao tratamento, além de manter a saúde pulpar e preservar a dentina residual, prevenindo a ocorrência de exposições pulpares acidentais (INNES et al., 2016; RICKETTS; INNES; SCHWENDICKE, 2018; SCHWENDICKE; FRENCKEN; INNES, 2018). Ela sempre deve ser empregada quando as lesões existentes não forem passíveis de limpeza mecânica eficiente e quando o selamento não for mais uma opção de tratamento viável (SCHWENDICKE; FRENCKEN; INNES, 2018). 
Nessa técnica, a realização das restaurações atua auxiliando o controle de biofilme por parte do paciente, protegendo o complexo dentinho-pulpar das agressões externas e promovendo a restauração da forma, função e estética dentária. Nessa perspectiva, a remoção de tecido cariado visa criar condições para a realização de uma restauração duradoura, preservando tecidos saudáveis e remineralizáveis, e obtendo uma vedação eficiente, que mantenha a saúde pulpar e maximize o sucesso do tratamento (SCHWENDICKE; FRENCKEN; INNES, 2018).

É importante salientar que o sucesso da remoção seletiva de cárie já foi constatado através de evidências clínicas, microbiológicas e radiográficas. A dentina intencionalmente deixada abaixo das restaurações apresenta-se como uma dentina escura e menos infectada. Logo, não deve ser feita a reabertura da cavidade apenas pela presença de alteração da cor dos tecidos dentários abaixo das restaurações (OLIVEIRA et al., 2006).

A remoção total ou não seletiva de tecido cariado não deve mais ser considerada como uma opção para o tratamento das lesões de cárie (SCHWENDICKE; FRENCKEN; INNES, 2018; AAPD, 2019; ABOPED, 2020). Apesar disso, o tratamento de dentes decíduos com cáries profundas ainda permanece controverso entre os profissionais, uma vez que a maioria dos dentistas alega que removeria todo o tecido cariado mesmo se o procedimento envolvesse risco de exposição pulpar (QUDEIMAT et al., 2007). Por outro lado, evidências apontam que a remoção seletiva de tecido cariado apresenta vantagem clínica no manejo da cárie, pois reduz a incidência de exposição da polpa (RICKETTS; INNES; SCHWENDICKE, 2018).

Dentro dessa abordagem da remoção seletiva de cárie, existe uma técnica chamada Tratamento Restaurador Atraumático (TRA), que consiste na remoção seletiva de tecido cariado por meio da utilização de instrumentos manuais e a realização da restauração definitiva da cavidade com cimento de ionômero de vidro de alta viscosidade. Ela é considerada uma técnica de mínima intervenção, pois promove máxima preservação do elemento dentário, além de não necessitar do uso de anestesia local, nenhum tipo de instrumento rotatório nem a utilização de isolamento absoluto. Em geral, é uma técnica bem aceita pelos profissionais, crianças e seus responsáveis, minimizando o medo e a ansiedade nos pacientes odontopediátricos frente ao atendimento, sendo uma excelente opção para crianças, pacientes ansiosos, fóbicos e portadores de necessidades especiais (FRENCKEN; HOLMGREN, 1999; HOLMGREN; ROUX; DOMEJEAN, 2013). Essa técnica vem sendo considerada o tratamento de escolha a ser empregado para o manejo de lesões de cárie com pequena ou média profundidade em odontopediatria, tanto em dentes decíduos quanto nos permanentes (ABOPED, 2020).

Além disso, uma das grandes vantagens do TRA é que ele pode ser utilizado em locais distantes e de difícil acesso, uma vez que não são necessários equipamentos odontológicos complexos, como o equipo, para que 0 atendimento seja realizado. Logo, esse tipo de tratamento pode auxiliar no tratamento em larga escala de populações carentes ao acesso à serviços odontológicos, podendo ser empregada até mesmo dentro de ambientes escolares (FRENCKEN; HOLMGREN, 1999; SILVA et al., 2012; HOLMGREN; ROUX; DOMEJEAN, 2013). 
Um dos materiais restauradores mais utilizados nas técnicas minimamente invasivas é o cimento de ionômero de vidro (CIV), tanto na cimentação da coroa de aço quanto no tratamento da remoção seletiva de cárie. O CIV é muito utilizado na área de odontopediatria devido as suas diversas propriedades, como a biocompatibilidade, liberação de flúor, adesão aos tecidos mineralizados e o coeficiente de expansão térmica semelhante ao dente. Além disso, apresenta baixo custo e de fácil manipulação (CROLL; NICHOLSON, 2002). Apesar disso, é importante enfatizar que o CIV indicado para a realização do TRA é o de alta viscosidade, apresentando alta taxa de sucesso e longevidade clínica (FRENCKEN; LEAL; NAVARRO, 2012), em especial nos dentes decíduos, com taxas de sucesso clínico de 95\% após 1 ano e 86\% após 3 anos de acompanhamento. No entanto, recomenda-se que o CIV de média viscosidade não seja usado para realização de restaurações na técnica do TRA (VAN'T HOF et al., 2006).

Independentemente do tipo de tratamento, a remoção do tecido cariado sempre deve ser feita de maneira mais cautelosa possível. Nesse sentido, existem ainda técnicas minimamente invasivas relacionadas ao método a ser usado para a remoção da cárie. Há o uso dos instrumentos manuais, que é a técnica convencionalmente mais empregada, e existem outras, como a utilização de jatos abrasivos e métodos químico-mecânicos. Não existem evidências suficientes para a recomendação de um método único de remoção de tecido cariado a ser empregado em todos os casos. Porém, a escavação manual ou quimio-mecânica apresentam-se como boas opções, especialmente para odontopediatria, uma vez que reduzem a dor e o desconforto durante 0 tratamento (SCHWENDICKE; FRENCKEN; INNES, 2018).

No sistema de preparo por jato abrasivo o desgaste dentário é causado pela energia dispersa pelo impacto das partículas abrasivas na cavidade. Diferente dos métodos convencionais, a pressão, o calor, a vibração e os ruídos quase não estão presentes no preparo por abrasão com óxido de alumínio, sendo essas grandes vantagens para utilização em odontopediatria. Essa técnica é mais conservadora do que os preparos tradicionais realizados com instrumentos rotatórios, e pode ser utilizada até mesmo em lesões iniciais de cárie. No entanto, uma das suas principais limitações é que essa técnica não é seletiva para remoção de dentina cariada, causando também o desgaste de tecidos dentários sadios durante a sua utilização (MOTISUKI et al., 2006).

As técnicas químico-mecânicas de remoção de tecido cariado consistem na aplicação de soluções que promovem o amolecimento seletivo da dentina cariada, facilitando sua remoção, que é realizada com auxílio de instrumentos manuais, como a colher de dentina. Para sua utilização, não é necessário o uso de anestesia local, mesmo em cavidades médias e profundas, podendo ser feitas sob isolamento relativo. Além disso, essas técnicas permitem a realização de posterior restauração com qualquer tipo de material restaurador (PERIC; MARKOVIC; PETROVIC, 2009). Dentre elas, destacam-se o uso de géis como Carisolv $^{\circledR}$, Papacárie ${ }^{\circledR}$ e Brix3000.

O Carisolv ${ }^{\circledR}$ é um gel composto por aminoácidos (ácido glutâmico, leucina e lisina) e hipoclorito de sódio a $0,5 \%$, utilizado em pequeno volume, entre 0,5 a $1 \mathrm{ml}$ por lesão de cárie. A preservação do tecido dental sadio, com preparos mais conservadores e sem dor, além da fácil aplicação e efetividade são consideradas 
vantagens da técnica. Diversas são as suas indicações, entre elas crianças e adolescentes, pacientes fóbicos ou com alto índice de dor, pacientes nos quais a anestesia seja contraindicada, lesões coronárias abertas e acessíveis e lesões cariosas próximas da polpa (FURE; LINGSTROM; BIRKHED, 2000). Já o Papacárie ${ }^{\circledR}$ é um produto a base de papaína, cloramina e azul de toluidina, que foi desenvolvido no Brasil em 2013. Com indicações e vantagens semelhantes, ele possui como vantagens a eficácia na remoção da cárie e, principalmente, o custo mais baixo em relação ao Carisolv $^{\circledR}$, tornando-o mais acessível aos pacientes no Brasil (PEREIRA et al., 2004). Comparando esses dois métodos, verificou-se que o uso do Carisolv ${ }^{\circledR}$ para remoção de cárie leva menos tempo do que o uso do Papacárie ${ }^{\circledR}$ ou dos procedimentos convencionais (HAMAMA et al., 2015).

O Brix300 é um gel enzimático atóxico, também a base de papaína (10\%), que possui uma tecnologia de bio encapsulamento de base aquosa, capaz de manter tanto a estabilidade do composto ativo quanto $\mathrm{o} \mathrm{pH}$ ideal para sua atuação, sem agredir os tecidos adjacentes nem a dentina saudável. Apresenta alta eficiência, sendo necessárias apenas 2 ou 3 aplicações do produto, durante 40 a 60 segundos, diretamente sobre a lesão a ser tratada. Sua utilização apresenta eficácia similar à remoção de cárie realizada por instrumentos rotatórios (TORRESI; BSERENI, 2017; ALKHOULI et al., 2020).

Nenhum desses produtos necessita de instrumentais específicos ou aparelhos sofisticados para sua utilização. Por outro lado, eles geram menor percepção de dor pelos pacientes do que o uso de instrumentos rotatórios para a remoção do tecido cariado, sendo assim uma boa opção para pacientes pediátricos. Após a aplicação pelo tempo indicado, o tecido cariado é removido com auxílio de um instrumento manual, geralmente uma colher de dentina, usando o lado oposto à sua ponta ativa e sem exercer pressão. Depois, é feita remoção do produto através de lavagem da cavidade com água, seguida de avaliação do tecido remanescente, a fim de verificar a necessidade de reaplicação, até que todo a dentina afetada tenha sido removida. Depois disso, o dente pode ser restaurado, usando a técnica e o material escolhido pelo profissional (HAMAMA et al., 2015; MARU; SHAKUNTALA; NAGARATHNA, 2015; TORRESI; BSERENI, 2017; ALKHOULI et al., 2020).

Vale ressaltar que uma das principais limitações de todas as técnicas minimamente invasivas descritas anteriormente é que elas são indicadas somente para os casos de pacientes assintomáticos e de lesões sem envolvimento pulpar. Em casos de lesões muito profundas, onde haja presença de sintomatologia ou sinais de envolvimento dos tecidos da polpa, não é possível realizar nenhuma dessas técnicas de mínima intervenção, sendo necessário instituir tratamentos mais radicais. Logo, enfatiza-se a importância do correto diagnóstico e da individualização da indicação do tratamento, que deve ser o mais adequado para cada caso (KIDD, 2012; RICKETTS et al., 2013; RICKETTS; INNES; SCHWENDICKE, 2018; SCHWENDICKE; FRENCKEN; INNES, 2018). Além disso, há ainda a dificuldade em conseguir que os pacientes e seus responsáveis estejam motivados e engajados com o tratamento da cárie, uma vez que a incorporação de novos hábitos de higiene bucal e de controle de dieta são difíceis, porém são fundamentais para assegurar o sucesso do tratamento e o controle da doença (UNKEL et al., 1995). 
O manejo contemporâneo da cárie dentária deve abranger a identificação do risco e compreensão do processo da doença para cada indivíduo, além de acompanhamento em relação à sua progressão e utilização dos serviços preventivos adequados, complementados por terapia reparadora somente quando indicada (AAPD, 2019). Quando realizadas de acordo com o correto diagnóstico e a indicação mais adequada para cada caso, todas as abordagens discutidas no presente trabalho apresentam comprovação científica da sua eficácia e elevadas chances de sucesso. Todas as técnicas para o tratamento minimamente invasivo das lesões de cárie atuam atrasando o início e desacelerando o ciclo restaurador destrutivo, preservando o tecido dentário, mantendo a sensibilidade pulpar e garantindo a permanência dos dentes e das restaurações dentárias durante o maior período de tempo possível (BANERJEE et al., 2017).

\section{CONCLUSÃO}

A utilização das técnicas minimamente invasivas para controle da cárie tem recebido cada vez mais destaque na literatura, porém a utilização de algumas dessas abordagens ainda é considerada controversa por alguns profissionais. Quando indicadas e realizadas corretamente, essas técnicas apresentam grandes vantagens, principalmente em odontopediatria, pois elas são mais rápidas, de execução mais simples e geram menos dor e ansiedade nos pacientes. Desta forma, é imprescindível que os profissionais, em especial os odontopediatras, ampliem seus conhecimentos sobre elas. Além disso, vale ressaltar que independente da técnica empregada, o controle de biofilme e da dieta são fundamentais para o sucesso do tratamento da cárie.

\section{REFERÊNCIAS}

ALKHOULI, M. M. et al. Comparing the efficacies of two chemo-mechanical caries removal agents $(2.25 \%$ sodium hypochlorite gel and brix 3000$)$, in caries removal and patient cooperation: A randomized controlled clinical trial. Journal of Dentistry, v. 93, p. 103280, 2020.

ALVES, L. S. et al. A randomized clinical trial on the sealing of occlusal carious lesions: 3-4-year results. Brazilian Oral Research, v. 31, e44, 2017.

AMERICAN ACADEMY OF PEDIATRIC DENTISTRY. The Reference Manual of Pediatric Dentistry: Definitions, Oral Health Policies, Recommendations, Endorsements, Resources: 2019-2020. American Academy of Pediatric Dentistry, p. 340-352, 2019.

ANTUNES, J. L.; NARVAI, P. C.; NUGENT, Z. J. Measuring inequalities in the distribution of dental caries. Community Dentistry and Oral Epidemiology, v. 32, n. 1, p. 41-48, 2004. 
ASSOCIAÇÃO BRASILEIRA DE ODONTOPEDIATRIA. Diretrizes para procedimentos clínicos em odontopediatria. São Paulo: Santos Publicações. 3. ed., 2020.

BAKHSHANDEH, A.; QVIST, V.; EKSTRAND, K. R. Sealing occlusal caries lesions in adults referred for restorative treatment: 2-3 years of follow-up. Clinical Oral Investigations, v. 16, n. 2, p. 521-529, 2012.

BANERJEE, A. et al. Contemporary operative caries management: consensus recommendations on minimally invasive caries removal. British Dental Journal, v. 223, n. 3, p. 215, 2017.

BRASIL. MINISTÉRIO DA SAÚDE. SECRETARIA DE ATENÇÃO À SAÚDE. SECRETARIA DE VIGILÂNCIA EM, S. SB Brasil 2010: Pesquisa nacional de saúde bucal: resultados principais. Brasília, 2012.

CROLL, T. P.; NICHOLSON, J. W. Glass ionomer cements in pediatric dentistry: review of the literature. Pediatric dentistry, v. 24, n. 5, p. 423-429, 2002.

DIAS, K. R. et al. Efficacy of sealing occlusal caries with a flowable composite in primary molars: A 2-year randomized controlled clinical trial. Journal of Dentistry, v. 74, n. 7, p. 49-55, 2018.

DONMEZ, S. B. et al. Clinical performance of aesthetic restorative materials in primary teeth according to the FDI criteria. European Journal of Paediatric Dentistry, v. 17, n. 3, p. 202-212, 2016.

FERRAZZANO, G. F.; INGENITO, A.; CANTILE, T. COVID-19 Disease in Children: What Dentists Should Know and Do to Prevent Viral Spread. The Italian Point of View. International Journal of Environmental Research and Public Health, v. 22, n. 17, p. 1-6, 2020.

FERREIRA, J. M. S. et al. Caries removal in primary teeth-A systematic review. Quintessence International, 43, n. 1, e9-15, 2012.

FINI, M. B. What dentists need to know about COVID-19. Oral Oncology, v. 28, n. 105 , p. 1-5, 2020.

FRENCKEN, J. E.; HOLMGREN, C. J. Atraumatic restorative treatment (ART) for dental caries. STI Book, 1999.

FRENCKEN, J. E.; LEAL, S. C.; NAVARRO, M. F. Twenty-five-year atraumatic restorative treatment (ART) approach: a comprehensive overview. Clinical Oral Investigations, v. 16, n. 5, p. 1337-1346, 2012.

FURE, S.; LINGSTROM, P.; BIRKHED, D. Evaluation of Carisolv (TM) for the chemo-mechanical removal of primary root caries in vivo. Caries Research, v. 34, n. 3, p. 275-280, 2000. 
HAMAMA, H. H. H. et al. Systematic review and meta-analysis of randomized clinical trials on chemomechanical caries removal. Operative dentistry, v. 40, n. 4, e167-e178, 2015.

HESSE, D. et al. Sealing versus partial caries removal in primary molars: a randomized clinical trial. BMC Oral Health, v. 14, p. 58, 2014.

HOLMGREN, C. J.; ROUX, D.; DOMEJEAN, S. Minimal intervention dentistry: part 5. Atraumatic restorative treatment (ART) - a minimum intervention and minimally invasive approach for the management of dental caries. British Dental Journal, v. 214, n. 1, p. 11-18, 2013.

HOLMGREN, C. et al. Minimal intervention dentistry II: part 3. Management of non-cavitated (initial) occlusal caries lesions - non-invasive approaches through remineralisation and therapeutic sealants. British Dental Journal, v. 216, n. 5, p. 237-243, 2014.

INNES, N. P. et al. A novel technique using preformed metal crowns for managing carious primary molars in general practice - a retrospective analysis. British Dental Journal, v. 200, n. 8, p. 451-454, 2006.

INNES, N. P.; EVANS, D. J.; STIRRUPS, D. R. The Hall Technique; a randomized controlled clinical trial of a novel method of managing carious primary molars in general dental practice: acceptability of the technique and outcomes at 23 months. BMC Oral Health, v. 7, p. 18, 2007.

INNES, N.; EVANS, D.; HALL, N. The Hall Technique for managing carious primary molars. Dental Update, v. 36, n. 8, p. 472-474, 2009.

INNES, N. P.; EVANS, D. J.; STIRRUPS, D. R. Sealing caries in primary molars: randomized control trial, 5-year results. Journal of Dental Research, v. 90, n. 12, p. 1405-1410, 2011.

INNES, N. P. et al. Managing Carious Lesions: Consensus Recommendations on Terminology. Advances in Dental Research, v. 28, n. 2, p. 49-57, 2016.

INNES, N. P. et al. The Hall Technique 10 years on: Questions and answers. British Dental Journal, v. 222, n. 6, p. 478-483, 2017.

INNES, N.; SCHWENDICKE, F.; FRENCKEN, J. An Agreed Terminology for Carious Tissue Removal. Monographs in Oral Science, v. 27, p. 155-161, 2018.

KASSEBAUM, N. J. et al. Global burden of untreated caries: a systematic review and metaregression. Journal of Dental Research, v. 94, n. 5, p. 650-658, 2015.

KIDD, E. Should deciduous teeth be restored? Reflections of a cariologist. Dental Update, v. 39, n. 3, p. 159-162, 2012. 
KIDD, E.; FEJERSKOV, O.; NYVAD, B. Infected Dentine Revisited. Dental Update, v. 42, n. 9, p. 802-806, 2015.

LULA, E. C. O. et al. Microbiological Analysis after Complete or Partial Removal of Carious Dentin in Primary Teeth: A Randomized Clinical Trial. Caries Research, v. 43, n. 5, p. 354-358, 2009.

MARU, V. P.; SHAKUNTALA, B. S.; NAGARATHNA, C. Caries removal by chemomechanical (Carisolv ${ }^{\mathrm{TM}}$ ) vs. rotary drill: a systematic review. The Open Dentistry Journal, v. 9, p. 462-472, 2015.

MOTISUKI, C. et al. The effectiveness of alumina powder on carious dentin removal. Operative Dentistry, v. 31, n. 3, p. 371-376, 2006.

OLIVEIRA, E. F. et al. The monitoring of deep caries lesions after incomplete dentine caries removal: results after 14-18 months. Clinical Oral Investigations, v. 10, n. 2, p. 134-139, 2006.

PAULSSON, L.; SÖDERFELDT, B.; BONDEMARK, L. Malocclusion traits and orthodontic treatment needs in prematurely born children. The Angle Orthodontist, v. 78, n. 5, p. 786-792, 2008.

PEREIRA, S. A. et al. Remoção químico mecânica de cárie por meio do gel Papacárie®. Revista Gaúcha de Odontologia, v. 52, n. 5, p. 385-388, 2004.

PERIC, T.; MARKOVIC, D.; PETROVIC, B. Clinical evaluation of a chemomechanical method for caries removal in children and adolescents. Acta Odontologica Scandinavica, v. 67, n. 5, p. 277-283, 2009.

QUDEIMAT, M. A. et al. Restorative treatment decisions for deep proximal carious lesions in primary molars. European Archives of Paediatric Dentistry, v. 8, n. 1, p. 37-42, 2007.

REBELO, M. A. B. et al. Does oral health influence school performance and school attendance? A systematic review and meta-analysis. International Journal of Paediatric Dentistry, v. 29, n. 2, p. 138-148, 2019.

RICKETTS, D.; INNES, N.; SCHWENDICKE, F. Selective Removal of Carious Tissue. Monographs in Oral Science, v. 27, p. 82-91, 2018.

RICKETTS, D. et al. Operative caries management in adults and children. The Cochrane Database of Systematic Reviews, v. 28, n. 3, p. CD003808, 2013.

RODE, S. E. M. et al. Daily biofilm control and oral health: consensus on the epidemiological challenge--Latin American Advisory Panel. Brazilian Oral Research, v. 26, n. Suppl 1, p. 133-143, 2012. 
SANTAMARÍA, R. M. et al. Alternative Caries Management Options for Primary Molars: 2.5-Year Outcomes of a Randomised Clinical Trial. Caries Research, v. 51 , n. 6, p. 605-614, 2018.

SCHWENDICKE, F.; FRENCKEN, J.; INNES, N. Clinical Recommendations on Carious Tissue Removal in Cavitated Lesions. Monographs in Oral Science, v. 27, p. 162-166, 2018.

SILVA, R. P. et al. Variations in caries diagnoses and treatment recommendations and their impacts on the costs of oral health care. Community Dental Health, v. 29, n. 1, p. 25-28, 2012.

SINGHAL, D. K.; ACHARYA, S.; THAKUR, A. S. Microbiological analysis after complete or partial removal of carious dentin using two different techniques in primary teeth: A randomized clinical trial. Dental Research Journal, v. 13, n. 1, p. 30-37, 2016.

TORRESI, F.; BSERENI, L. Eficácia do método de remoção químico-mecânica da cárie dentária como papaína em adultos. Revista da Associação Paulista de Cirurgiões Dentistas, v. 71, n. 3, p. 266-269, 2017.

TUMENAS, I. et al. Odontologia minimamente invasiva. Revista da Associação Paulista de Cirurgiões Dentistas, v. 68, n. 4, p. 283-295, 2014.

UNKEL, J. H. et al. Toothbrushing ability is related to age in children. Journal of Dentistry for Children, v. 62, n. 5, p. 346-348, 1995.

VAN DER ZEE, V.; VAN AMERONGEN, W. E. Short communication: Influence of preformed metal crowns (Hall technique) on the occlusal vertical dimension in the primary dentition. European Archives of Paediatric Dentistry, v. 11, n. 5, p. 225-227, 2010.

VAN'T HOF, M. A. et al. The Atraumatic Restorative Treatment (ART) approach for managing dental caries: A meta-analysis. International Dental Journal, v. 56, n. 6, p. 345-351, 2006. 